\title{
Melt Segregation From Partially Molten Source Regions: The Importance of Melt Density and Source Region Size
}

\author{
Edward Stolper,' David Walker, ${ }^{2}$ Bradford H. Hager,' AND James F. Hays ${ }^{2}$
}

\begin{abstract}
The compressibility of basic melt at 1 atmosphere is about an order of magnitude higher than that of mantle minerals. Consequently, the density contrast between melt and the principal residual crystals in mantle source regions is expected to decrease with increasing source region depth. The increasingly olivine-normative character of primary melts produced at greater depths is also expected to result in a decrease in this density contrast with increasing source region depth. Once vertical permeability is established by melt generated during partial melting, buoyancy-driven melt percolation can under some circumstances segregate melt from the residual crystals in its source region on a geologically rapid time scale. Limits to this process are provided by cooling of the source region (freezing melt in) and rigidity of the crystalline matrix (mechanically trapping melt). Source region size influences these limits strongly: consequently, small, partially molten diapirs ( $\sim \mathrm{km}$ in diameter) may be able to trap large melt fractions $(z 30 \%)$, but larger source regions would be unable to do so. The reduction in density contrast with pressure reduces the buoyent force driving melt percolation and provides another limit to melt segregation. Diapirs at depth may thus stably contain large fractions of melt but may decompress and unload their melt during ascent; this effect would be enhanced in small diapirs and may be relevant to the genesis of komatiitic magma. Melt compression may also be a factor in explaining why the very different maximum depths inferred for typical basic melt segregation from source regions on different planets $-\sim 500 \mathrm{~km}$ on the moon, $\sim 250 \mathrm{~km}$ on Mars, $\sim 100 \mathrm{~km}$ on earth-correspond to similar pressures (25-35 kbar); at greater pressures, melt may no longer be capable under ordinary conditions of segregating upwards by buoyancy. This may also help to explain why depleted peridotites overlie more fertile peridotites and how deep regions of the mantle are able to remain fertile over geologic time.
\end{abstract}

\section{INTRODUCTION}

Nearly every stage in the genesis of magma is influenced to some extent by the density contrast between silicate liquids and crystals. The rate of liquid segregation from partially molten source regions is a function of the difference in density between the melt and the residual crystals. This rate of liquid segregation, in turn, exerts a major control on whether the fusion process will be closer to equilibrium or fractional fusion and on the degree of partial melting that can be achieved in a source region before melt segregation occurs. The flow of magma in conduits from these source regions towards the surface is also influenced by a density contrast, in this case between the magma and the country rock. Small density contrasts can lead to slow ascent rates and more opportunity for fractionation and contamination of the magma en route to the surface. If the country rock is less dense than the magma, pooling of the magma can occur, providing a site for intrusion and extensive fractionation of the parent magma. This last effect can also produce a bias in the compositions of erupted magmas, favoring those magmas that are less dense than the crustal rocks that must be traversed en route to the surface. The rate of crystal settling (or rising) in the magmas will be influenced by the density contrast between the melt and crystals, and this will play an important part in determining the role of crystal fractionation in petrogenesis.

In this paper, we explore the changes expected in the density contrast between basic melts and peridotites with increasing pressure using the limited data available on the compressibilities of silicate melts and data on the densities of mantle minerals. We conclude that since compressibilities of silicate

\footnotetext{
${ }^{1}$ Division of Geological and Planetary Sciences, California Institute of Technology, Pasadena, California 91125.

2 Department of Geological Sciences, Harvard University, Cambridge, Massachusetts 02138.
}

Copyright ( 1981 by the American Geophysical Union. melts are about an order of magnitude greater than those of mantle minerals, the density contrast between basic melts and mantle minerals must diminish significantly with increasing pressure. We then enlarge upon our earlier analysis of the migration of liquid in partially molten source regions [Walker et al., 1978], paying particular attention to the influence of the diminished density contrast between melt and residual crystals with increasing source region depth and to the influence of source region size. This analysis leads to several generalizations concerning the factors influencing the depths at which magmas will segregate from their source regions and the degrees of partial melting that can be achieved in these source regions before melt segregation occurs.

\section{Densities of basic liquids at High Pressures Equation of State Data}

In order to model the migration of melt in source regions, the densities of melts at the pressures corresponding to these source regions must be known. In principle, such densities could be measured directly with the 'falling sphere' technique pioneered by Kushiro and his co-workers [Kushiro et al., 1976; Fujï and Kushiro, 1977a, b; Scarfe et al., 1979]. However, the pressure and compositional ranges over which these data are available are at present rather limited. We have therefore tried to estimate the densities of basic liquids as a function of pressure using a third-order Birch-Murnaghan equation of state [Birch, 1952]:

$$
\begin{aligned}
& P=\frac{3}{2} \cdot K_{T}^{0} \cdot\left\{\left(\frac{\rho}{\rho_{0}}\right)^{7 / 3}-\left(\frac{\rho}{\rho_{0}}\right)^{5 / 3}\right\} \\
& \cdot\left\{1-\frac{3}{4} \cdot\left(4-K_{T}^{\prime}\right) \cdot\left[\left(\frac{\rho}{\rho_{0}}\right)^{2 / 3}-1\right]\right\}
\end{aligned}
$$

where $\rho_{0}$ is the 1 atmosphere density of the liquid, $K_{T}{ }^{0}$ is the 1 atmosphere isothermal bulk modulus of the liquid, and $K_{T}{ }^{\prime}$ is the pressure derivative of the isothermal bulk modulus. 
TABLE 1. One Atmosphere Bulk Moduli of Silicate Liquids

\begin{tabular}{lcl}
\hline \multicolumn{1}{c}{ Comparison } & $K_{s}$ mbar & \multicolumn{1}{c}{ Reference } \\
\hline $\mathrm{Na}_{2} \mathrm{O}-\mathrm{SiO}_{2}$ & $0.14-0.17$ & Bockris and Kojonen [1960] \\
$\mathrm{K}_{2} \mathrm{O}-\mathrm{SiO}_{2}$ & $0.07-0.13$ & Bockris and Kojonen [1960] \\
$\mathrm{Li}_{2} \mathrm{O}-\mathrm{SiO}_{2}$ & $0.05-0.20$ & Bloom and Bockris [1957] \\
$\mathrm{K}_{2} \mathrm{O}-\mathrm{SiO}_{2}$ & $0.08-0.13$ & Laberge et al. [1973] \\
$\mathrm{Li}_{2} \mathrm{O}-\mathrm{SiO}_{2}$ & $0.14-0.20^{*}$ & Baidov and Kunin [1968] \\
$\mathrm{K}_{2} \mathrm{O}-\mathrm{SiO}_{2}$ & $0.07-0.12^{*}$ & Baidov and Kunin [1968] \\
$\mathrm{CaO}_{2} \mathrm{SiO}$ & $0.18-0.31^{*}$ & Baidov and Kunin [1968] \\
$\mathrm{Na}_{2} \mathrm{O}-\mathrm{K}_{2} \mathrm{O}-\mathrm{SiO}_{2}$ & 0.2 & Kumazawa et al. $[1964]$ \\
$\mathrm{Na}_{2} \mathrm{O}-\mathrm{K}_{2} \mathrm{O}-\mathrm{CaO}-\mathrm{SiO}_{2}$ & 0.13 & Murase and McBirney [1973] \\
Basalts, andesite & $0.14-0.15$ & Murase and McBirney [1973] \\
Basalt & 0.12 & Murase et al. $[1977]$ \\
Basalt & 0.17 & Manghnani et al. $[1981]$ \\
Assorted basalts, & $0.1-0.2$ & Murase and Suzuki [1966] \\
andesites, rhyolites, & & \\
synthetics & & \\
\hline
\end{tabular}

*Excludes 0.75 mbar point for pure $\mathrm{SiO}_{2}$.

The densities of basaltic liquids at 1 atmosphere $\left(\rho_{0}\right.$ in (1)) can be calculated to an accuracy of about $1 \%$ [Bottinga and Weill, 1970; Nelson and Carmichael, 1979].

Table 1 shows the adiabatic bulk moduli, $K_{s}{ }^{0}$, of a variety of silicate liquids at 1 atmosphere, all measured by ultrasonic methods. These bulk moduli ( $0.05-0.3$ mbar) are about an order of magnitude lower than those of expected mantle minerals (1-2 mbar [Ahrens, 1973]). Murase and McBirney [1973] showed that these low values of the bulk moduli of silicate liquids are consistent with the systematic relation between bulk modulus and volume per ion pair established by Anderson and Nafe [1965] for crystalline materials and do not necessarily imply any unusual behavior of the melts relative to the solids under compression. These bulk moduli appear to be insensitive to temperature (i.e., $\left.\left(\partial K_{S}{ }^{0} / \partial T\right)_{P} \sim 0\right)$ within several hundred degrees of the liquidus [Bloom and Bockris, 1957; Bockris and Kojonen, 1960; Murase and McBirney, 1973; Laberge et al., 1973; Manghnani et al., 1981] and to bulk composition even over a range extending from basalts to silica-rich, alumina-free synthetic compositions [Murase and McBirney, 1973]. A correction must be applied to the adiabatic bulk moduli given in Table 1 to obtain values for the isothermal bulk moduli needed to calculate high pressure densities. However, Murase and McBirney [1973] showed that for silicate melts, for which a Gruneisen's parameter of about 0.2 can be calculated at 1 atmosphere, the isothermal bulk modulus will only be about $1 \%$ lower than the adiabatic bulk modulus, a difference that for our purposes, and in view of the uncertainties in $K_{s}^{0}$, is negligible.

There are essentially no data on the compressibilities of silicate melts above 1 atmosphere, hence values of $K_{T}^{\prime}$ must be estimated by indirect methods. For crystalline materials, a relationship appears to exist between mean atomic weight, density and $K_{T}^{\prime}$ [Anderson et al., 1968; Chung, 1973; Anderson, 1973]. This relationship suggests that basaltic melt, with a mean atomic weight of 21-22 and a density of approximately $2.7 \mathrm{~g} / \mathrm{cm}^{3}$, would have a $K_{T}^{\prime}$ of 6-7. Some justification for application of the systematics developed for solids to liquid silicates may come from the observation, noted above, that the $K_{S}{ }^{0}$ values measured for liquid silicates are consistent with the empirical relationships between $K_{T}{ }^{0}$, mean atomic weight, and density established by the solids [Murase and McBirney, 1973].

Although we will set $K_{T}^{\prime}=6-7$ in calculating the densities of basic magmas at high pressures, we note that it is possible that silicate melts will exhibit anomalous behavior. The bulk modules of silica glass actually decreases with increasing pressure up to a pressure of $20 \mathrm{kbar}\left(K_{T}^{\prime}=-6.15\right.$ at $P=1$ atm) and then begins to increase; $K_{T}^{\prime}$ reaches a value of about 5 at 30 kbar [Peselnick et al., 1967; Skelton, 1978]. If silicate liquids undergo a structural transformation with increasing pressure (e.g., $A l^{\text {iv }} \rightarrow \mathrm{Al}^{\mathrm{v}}$ ), as suggested by several authors [e.g., Waff, 1975; Kushiro et al., 1976], then $K_{T}^{\prime}$ will decrease, and perhaps even become negative, in the pressure range over which the structural change occurs since the liquid will appear to be anomalously compressible in this region. If either of these effects is important in silicate melts, our estimates of density will be lower than the true densities of melts at high pressures. We note, however, that recent work has suggested that the $\mathrm{Al}^{\mathbf{l v}} \rightarrow \mathrm{Al}^{\mathrm{v} 1}$ transformation does not occur in silicate melts, at least to 40 kbar pressure [Sharma et al., 1979; Mysen et al., 1980]. We also note that although the $K_{T}^{\prime}$ values of 6-7 that we have taken for silicate melts are consistent with those measured for water and a wide variety of organic liquids $\left(K_{T}{ }^{\prime}\right.$ = 5-10 [e.g., Bridgman, 1913]), higher values have been observed: Spetzler et al. [1975] measured values of $K_{T}^{\prime}$ as high as 15.5 for liquid mercury at $900^{\circ} \mathrm{K}$.

The densities of two basalts, a 1921 Kilauea tholeiite and a mid-ocean ridge tholeiite, have been calculated to $30 \mathrm{kbar}$ using the Birch-Murnaghan equation of state, with 1 atmosphere liquid densities calculated according to Bottinga and Weill [1970] or actually measured, $K_{T}^{0}=0.115-0.2 \mathrm{mbar}$, and $K_{T}{ }^{\prime}=6-7$. The results of these calculations are shown in Figure 1. These two basalts were chosen as a check on our calculations since densities of both have been measured at pressures higher than $1 \mathrm{~atm}$ by the falling sphere technique [Fujii and Kushiro, 1977a, b]. The limited data on the mid-ocean ridge tholeiite are reproduced well by $K_{T}{ }^{0}=0.2 \mathrm{mbar}$ and $K_{T}{ }^{\prime}$ = 6-7. The data on the 1921 Kilauea tholeiite, however, require some comment. Fujii and Kushiro [1977a] reported that Murase measured the density of this sample at 1 atmosphere and obtained a value of $2.62 \mathrm{~g} / \mathrm{cm}^{3}$. The calculated density for this composition, based on the partial molar volumes in Bottinga and Weill [1970] or on those given by Nelson and Carmichael [1979], is between 2.69 and $2.72 \mathrm{~g} / \mathrm{cm}^{3}$ if $85-100 \%$ of the iron is taken as ferrous iron. The reason for the discrepancy between the measured and calculated values is unknown. If the lower 1 atmosphere density of $2.62 \mathrm{~g} / \mathrm{cm}^{3}$ is used in (1), all of the falling sphere data points are consistent with $K_{T}{ }^{0}=$ 0.115 mbar, the value measured for this sample by Murase et al. [1977]. If a 1 atmosphere density of $2.70 \mathrm{~g} / \mathrm{cm}^{3}$ is assumed, then the measured densities at 5 and $7.5 \mathrm{kbar}$, which are also approximately $2.70 \mathrm{~g} / \mathrm{cm}^{3}$, are difficult to understand, implying a bulk modulus significantly higher than any that have been measured for silicate melts. The $15 \mathrm{kbar}$ measurement of density, however, is consistent with $\rho_{0}=2.70 \mathrm{~g} / \mathrm{cm}^{3}, K_{T}{ }^{0}=0.2$ mbar, and $K_{T}{ }^{\prime}=6-7$.

Despite the obvious uncertainties associated with the few experimentally determined values of silicate melt densities at high pressures and those associated with our chosen values of $K_{T}^{0}$ and $K_{T}$, we believe that estimates of densities of basic silicate melts calculated from (1) using these values provide a basis for speculating on the petrological consequences of the higher densities of magmas at depth in the earth.

\section{Densities of Primary Magmas}

It is widely believed that most basalts, including the Kilauea tholeiite and the mid-ocean ridge basalt composition 

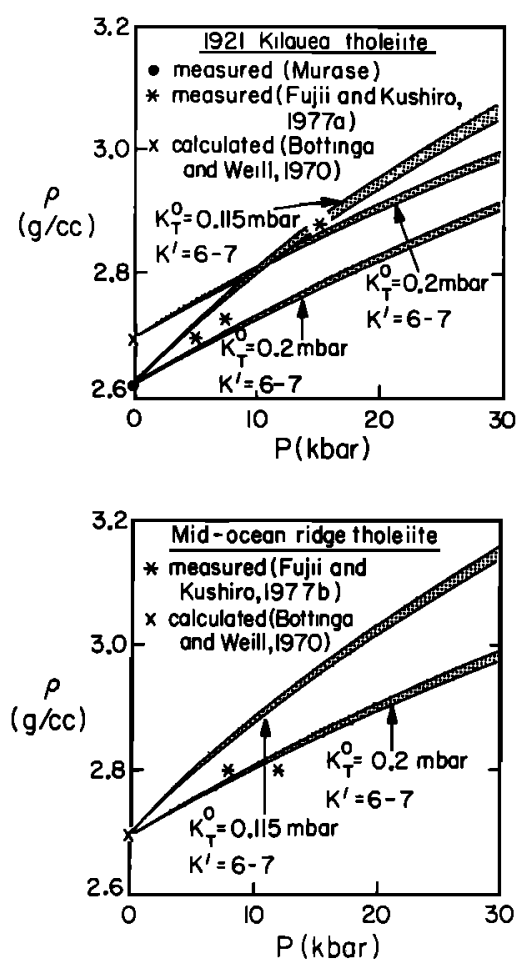

Fig. 1. Comparison of experimentally determined densities of basaltic liquids at pressures of 5-15 kbar [Fujii and Kushiro, 1977a, b] with densities calculated from (1). The calculation is discussed in the text.

shown in Figure 1, have undergone fractionation of olivine prior to solidification [e.g., O'Hara, 1968a, b; Irvine, 1977; Bender et al., 1978; Green et al., 1979; Stolper, 1980]. Stolper and Walker [1980] have examined the effects of fractionation of olivine and other crystalline phases from basic liquids at 1 atmosphere on the densities of residual liquids. Fractionation of olivine-only produces residual liquids with lower densities at their liquidi than their parental liquids. The density of the putative picritic parent liquid of mid-ocean ridge tholeiites at its liquidus is about $2.75 \mathrm{~g} / \mathrm{cm}^{3}$ [Stolper and Walker, 1980]. The parent liquid of the Kilauea tholeiites [Irvine, 1977] would have essentially the same density. Komatiitic liquids would have even higher densities, between 2.8 and $2.9 \mathrm{~g} / \mathrm{cm}^{3}$.

Figure 2 shows the calculated variation of density with pressure for a liquid having a density at 1 atmosphere of $\mathbf{2 . 7 5}$ $\mathrm{g} / \mathrm{cm}^{3}$. The liquid densities shown in Figure 2 were calculated by substituting values of $K_{T}{ }^{0}=0.115-0.2 \mathrm{mbar}$ and $K_{T}{ }^{\prime}=6-7$ into (1). For comparison, a density model of the mantle [Dziewonski et al., 1975], the densities of fertile peridotite minerals along a continental geotherm, of olivine at the liquidus of a komatiite, and of eclogite at its solidus are also shown in Figure 2.

A constant value of $\rho_{0}$ was used in calculating the liquid densities in Figure 2. Since the liquidus temperatures of basaltic compositions increase with increasing pressure, $\rho_{0}$ should be adjusted for the liquidus temperature at each pressure. This correction, however, will be comparatively small. The slope of the olivine liquidus is no more than $5^{\circ}-10^{\circ} \mathrm{C} / \mathrm{kbar}$. This would involve a correction to $\rho_{0}$ of less than $0.10 \mathrm{~g} / \mathrm{cm}^{3}$ over $50 \mathrm{kbar}$, based on calculations of density using the partial molar volumes of Bottinga and Weill [1970]. The uncertainty in the choice of $\rho_{0}=2.75 \mathrm{~g} / \mathrm{cm}^{3}$ for the parental picritic liq- uids is nearly this large. In addition, the decrease in $K_{T}{ }^{\circ}$ that will be produced by increasing the temperature will, to an unknown extent, offset the effects of decreasing $\rho_{0}$. An effort to deal with the temperature correction more quantitatively is described below and incorporated into Figure 3.

Figure 2 demonstrates clearly that the density contrast between basic melts and mantle minerals diminishes with increasing pressure. This reflects the fact that the liquids are an order of magnitude more compressible than the solids at 1 atmosphere. The value of the density contrast predicted at high pressure depends, of course, on the parameters used in (1). For $K_{T}{ }^{\circ}=0.2 \mathrm{mbar}$, at the high end of the range of values reported for silicate liquids (Table 1 ), the density contrast between liquid and olivines, pyroxenes, and bulk peridotite decreases from about $0.4-0.6 \mathrm{~g} / \mathrm{cm}^{3}$ at 1 atmosphere, to 0.10 $0.25 \mathrm{~g} / \mathrm{cm}^{3}$ by $40 \mathrm{kbar}$, and is essentially zero at $80 \mathrm{kbar}$. For $K_{T}{ }^{\circ}=0.115$ mbar, the value measured ultrasonically for the Kilauea tholeiite by Murase et al. [1977], the density contrast has essentially disappeared by $\mathbf{4 0} \mathrm{kbar}$, and the density of the melt is actually greater than that of olivine, pyroxenes, and bulk peridotite at higher pressures. Though perhaps anti-intuitive, this type of behavior is not prohibited theoretically. We do, however, think it unlikely that the liquid density would ever exceed that of eclogite, the crystalline equivalent of these basaltic compositions; this suggests that a $K_{T}{ }^{\circ}$ of 0.115 mbar is too low or that $\mathrm{K}_{\mathrm{T}}{ }^{\prime}$ must be somewhat higher than 6-7. Most of the other measured values of $K_{T}{ }^{\circ}$ on rock compositions (Table 1) are between 0.14 and $0.18 \mathrm{mbar}$; for these values, the density versus pressure relationship would be intermediate between those shown in Figure 2 . The density of the melt would equal that of average mantle peridotite at pressures between 50 and $70 \mathrm{kbar}$ (actually, at somewhat higher pressures if the thermal expansion of the liquid were considered), and approach that of eclogite asymptotically at higher pressures. However, in the absence of more data, the details of the density relations at these pressures cannot be resolved.

Figure 2 shows the calculated variation in density of a single liquid composition (in this case, the picritic sort of liquid envisioned as parental to mid-ocean ridge and Kilauean tholeiites that probably could be equilibrated with residual mantle peridotite at $20-30 \mathrm{kbar}$ ) as a function of pressure. As mentioned above, a constant value of $\rho_{0}$ was used in calculating these liquid densities. However, since we are interested in the variations in density of melts at the temperatures and pressures of their source regions, we must have some notion of the change in temperature and in liquid composition in these partially molten source regions as a function of pressure. In general, the liquids produced on melting of peridotites become more olivine-normative with increasing pressure; this is certainly true to pressures as high as $\mathbf{4 0} \mathrm{kbar}$. In addition to being more olivine-normative, the primary melts produced at greater depths will also have higher liquidus temperatures than those produced at shallow depths and may be more alkaline. The increase in normative olivine tends to increase $\rho_{0}$ while the increasing liquidus temperature tends to decrease it. Based on the results of Presnall et al. [1979], which give the compositions of liquids in equilibrium with peridotitic minerals in the simplified $\mathrm{CaO}-\mathrm{MgO}-\mathrm{Al}_{2} \mathrm{O}_{3}-\mathrm{SiO}_{2}$ system as a function of pressure up to $20 \mathrm{kbar}$, the compositional effects outweigh the temperature effect, leading to a net increase in $\rho_{0}$ of primary liquids generated at higher pressures. This is shown in Figure 3. Figure $3 a$ shows the densities at 1 atmosphere of 


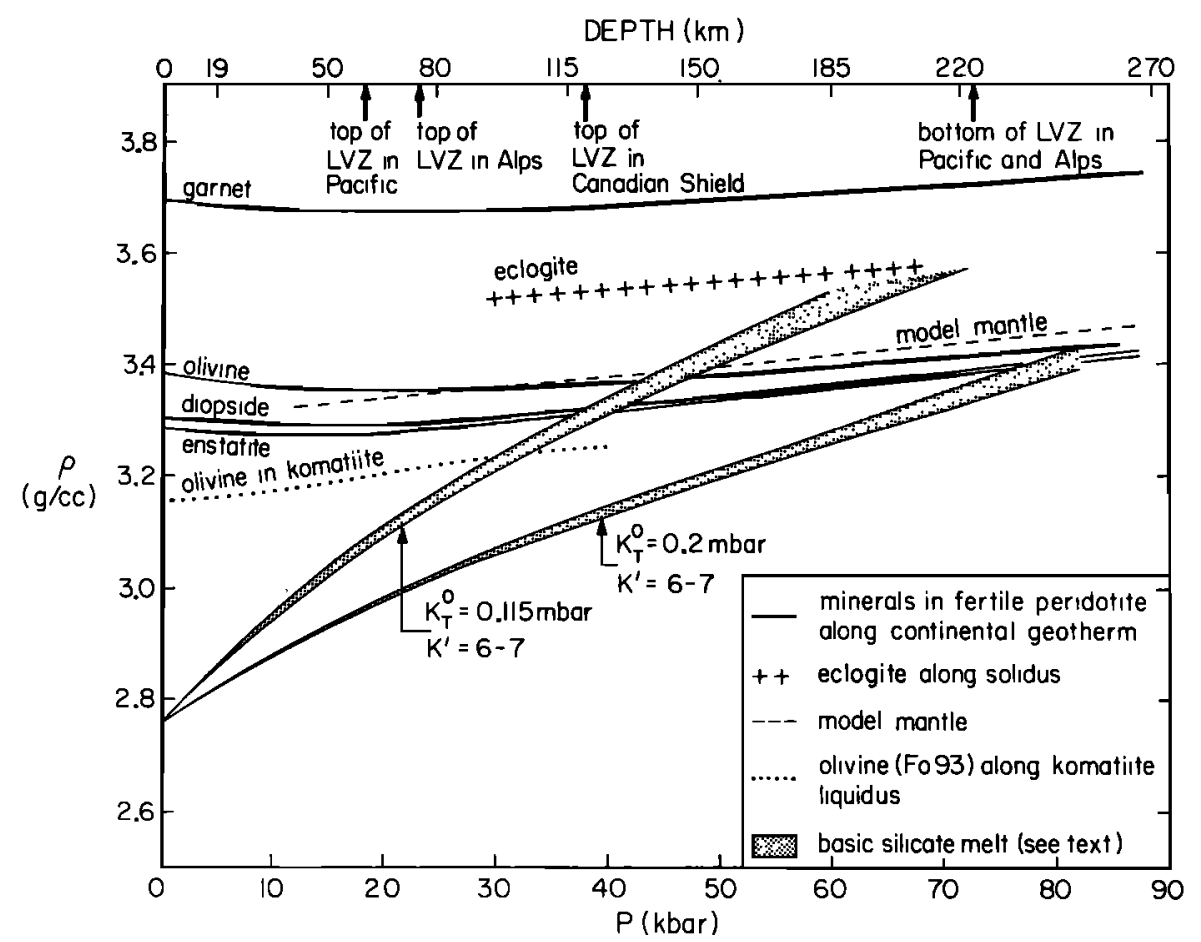

Fig. 2. Comparison of the density of basic silicate melt, calculated using (1) and the parameters discussed in the text, and the densities of possible mantle rocks and minerals. The model mantle is from Dziewonski et al. [1975]. The density of eclogite at its solidus is after Clark and Ringwood [1964], corrected to the eclogite solidus of Howells et al. [1975] using a volume coefficient of thermal expansion of $2 \cdot\left(10^{-5}\right){ }^{\circ} \mathrm{C}^{-1}$. High pressure densities of individual minerals in 'fertile' garnet 1 herzolite were calculated along the continental geotherm [Mercier and Carter, 1975] from (1) using the measured 1 atm densities given by Boyd and McCallister [1976], volume coefficient of thermal expansion data from Skinner [1966] and Cameron et al. [1973] and bulk moduli and their $P-T$ derivatives from Levien et al. [1979], Soga [1967], Graham and Barsch [1969], Liebermann and Mayson [1976], and Olinger [1977]. Densities of olivine (Fo 93) along a komatiite liquidus [Bickle et al., 1977] were calculated in the same way, using a 1 atm density based on Hazen [1977] and the bulk modulus from sources cited above. Approximate depths to top and bottom of low-velocity zone are from Dorman [1969].

the model 'primary' liquids that would be generated at the dry peridotite solidus at pressures up to 20 kbar. These were calculated at the temperatures of the experiments at which they were equilibrated with the model peridotite assemblages. Despite the increase in the temperature of generation of these model primary liquids with increasing pressure, their 1 atmosphere densities still increase with the pressure of their generation, at least up to $20 \mathrm{kbar}$, due to their compositional changes. We note that these compositional changes include, insofar as is possible in the simplified, alkali-free system, an increase in alkalinity with increasing pressure [Presnall et al., 1979]. In Figure 3b, these 1 atmosphere densities are then extrapolated up to the conditions at which the model primary liquids were in equilibrium with mantle minerals, using $K_{T}{ }^{\circ}=$ 0.2 mbar and $K_{T}^{\prime}=6$. With the parameters used to calculate Figure 3, the density contrast between the residual minerals in the simplified peridotite system and the 'primary' magmas in this simplified system diminishes from about $0.50 \mathrm{~g} / \mathrm{cm}^{3}$ at 1 atmosphere to about $0.27 \mathrm{~g} / \mathrm{cm}^{3}$ at $20 \mathrm{kbar}$. These results on the model peridotite system suggest that the change in composition of primary magmas with depth will accelerate the decrease in the density difference between the principal peridotite minerals and their partial melts beyond what would be suggested by Figure 2, where only the effects of compression on a melt of constant composition and $\rho_{0}$ are considered. Currently available data, however, are inadequate to verify quantitatively that the effects observed in the simplified analog system apply to the natural system or that the compositional changes continue to outweigh the effects of thermal expansion at pressures higher than 20 kbar.

\section{Stability of Melt in Permeable Bodies}

In an earlier analysis of melt migration in the mantle, we examined the hypothesis that the low-velocity zone (LVZ) could be a partially molten zone of the mantle [Walker et al., 1978]. We concluded that a geologically persistent LVZ due to a homogeneous distribution of melt could only be maintained if the melt fraction were on the order of $0.1 \%$ or less. If the amount of melt were greater than this, it would drain off rapidly $\left(<10^{8}\right.$ years). We suggested that if it were present in the LVZ, melt might represent a drainage residue.

The top of the LVZ lies between 50 and $120 \mathrm{~km}$ depth in the mantle ( 15-40 kbar) and the bottom is near $220 \mathrm{~km}$ depth ( 70 kbar) [Dorman, 1969]. As seen in Figure 2, this is the depth range over which we would predict that the density contrast between dry basic melt and mantle peridotite becomes small. Our earlier analysis of melt stability in the LVZ requires reinspection since we assumed a density contrast of $0.7 \mathrm{~g} / \mathrm{cm}^{3}$ and did not consider the effects, discussed above, of compression on this density contrast. The smaller density contrasts implied by Figure 2 might lead to more effective stabilization of melt against buoyancy-driven percolative melt segregation in the LVZ. As we will show in the following discussion, this expectation is qualitatively realized, but $\Delta \rho$ may have to become very small to effectively stabilize the 


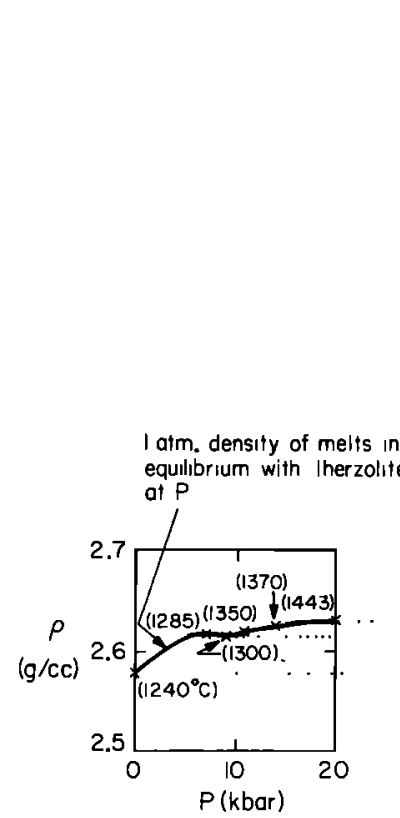

(a)

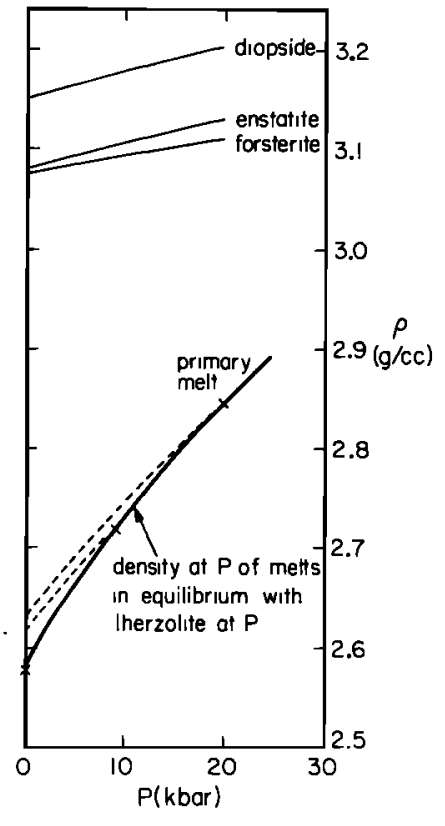

(b)
Fig. 3. (a) One atmosphere densities of liquids in equilibrium (at pressures between $1 \mathrm{~atm}$ and $20 \mathrm{kbar}$ ) with olivine + enstatite + diopsidic clinopyroxene + (anorthite \pm spinel) in the system $\mathrm{CaO}-\mathrm{MgO}-$ $\mathrm{Al}_{2} \mathrm{O}_{3}-\mathrm{SiO}_{2}$ at the temperatures of their equilibration with the lherzolite assemblage [Presnall et al., 1979] calculated from Bottinga and Weill [1970]. (b) Densities of liquids shown in Figure 3a calculated at the pressures of their equilibration with a lherzolitic assemblage using (1) and the parameters given in the text. Also shown are the calculated densities of the forsterite, enstatite, and diopside in the lherzolitic assemblages, calculated as described for Figure 2, using 1 atm densities for the Mg-end-member minerals.

LVZ. However, for smaller bodies such as rising diapirs, the effect of melt compressibility may be quite important.

In order to explore the fate of melt in the LVZ or other reservoirs of partially molten rock, we must know the time scales of melt percolation, reservoir freezing, and reservoir plasticity. Melt will be trapped if the reservoir freezes faster than melt percolates, while percolation velocity may be limited by the rate at which the reservoir deforms.

Melt velocity, $V_{m}$, is given by

$$
V_{m}=\frac{k \cdot \nabla P}{\eta}=\frac{\Delta \rho \cdot g \cdot k}{\eta}
$$

if resistance to melt percolation rather than deformation of the matrix is the limiting factor. $(\nabla P$ is the pressure gradient within the melt, $g$ is gravitational acceleration, $\Delta \rho$ is the density contrast between melt and crystalline reservoir, and $\eta$ is melt viscosity.) Reservoir permeability, $k$, can be taken to be related to melt fraction, $f$, by [Walker et al., 1978]

$$
k=\frac{R^{2} \cdot f^{2}}{\chi}
$$

where $R$ is the grain size and $\chi$ is a constant depending on melt geometry, taken as $\mathbf{7 3 . 5}$ for truncated octahedral grains with melt on triangular three-grain channels [Waff and Bulau, 1979].

Melt accumulation can only occur when melt at a given depth has a smaller velocity than melt at a slightly greater depth, leading to a local increase in concentration. If $k, g$, and $\eta$ are constant and $\Delta \rho$ is either constant or decreases with depth, this condition for melt segregation cannot be met. Cooling of the top of the partially molten zone, however, leads to a decrease in $f$ through solidification as well as an increase in the (temperature dependent) melt viscosity. Both effects lead to a decrease in melt velocity near the solidification front that tends to cause melt segregation.

Jaeger [1957] gave an elegant approximate solution to the cooling of a partially molten body that provides useful insight into the physics of this problem. The depth to the solidus from the top of the intrusion, $d_{s}$ at time $t$ is given by

$$
d_{s}=2 \cdot \lambda \cdot(\kappa \cdot t)^{1 / 2}
$$

where $\lambda$ is a number of order unity (see Table 2) given by the solution for a transcendental equation [Jaeger, 1957] and $\alpha$ is thermal diffusivity (taken as $0.01 \mathrm{~cm}^{2} / \mathrm{s}$ ). The average downward velocity of the solidus $\nabla_{s}$ is then

$$
\bar{V}_{s}=\frac{4 \cdot \lambda^{2} \cdot \kappa}{d_{s}}
$$

while the instantaneous velocity $V_{s}$ is

$$
V_{s}=\lambda \cdot\left(\frac{\kappa}{t}\right)^{1 / 2}=\frac{\bar{V}_{s}}{2}
$$

At any given time, for depths greater than $d_{s}$, the body has begun to cool but has not completely solidified. This partial cooling slows the upward movement of melt by decreasing $f$ (and hence $k$ ) and increasing melt viscosity, thereby initiating melt segregation. The temperature profile has a shape given by the error function, starting at the solidus temperature, $T_{s}$ at a depth $d_{s}$ and increasing to the initial intrusion temperature, $T_{b}$, at great depth [Jaeger, 1957]. Numerical experiments show that melt segregation begins at the 'knee' of the error function temperature profile $\left(T-T_{s} \sim 0.75\left(T_{i}-T_{s}\right)\right)$. The velocity, $V_{c}$ of this 'knee' depends only weakly on the details of the problem, ranging from one to two and a half times that of the solidus $\left(V_{s}\right)$ for melt fractions varying from 0.002 to 0.2 for the parameters used (see Table 2).

As can be seen from (6), the velocity of the solidus, and hence the velocity of the chill zone that precedes it, is initially very large. Only when sufficient time has elapsed that the velocity of the chill zone downward is comparable to that of the melt percolation velocity upward can melt segregate in a region before that region is further chilled and frozen. Taking $1.2(f \cong 0.05)$ as a representative value of $V_{c} / V_{s}$ (see Table 2) and equating $V_{m}$ and $V_{c}$ give for the time at which segregation by percolation occurs

$$
t_{p}=1.5 \cdot \kappa \cdot\left(\frac{\lambda \cdot \eta}{g \cdot \Delta \rho \cdot k}\right)^{2}
$$

During this time, the melt that forms the initial segregation will have traveled upwards a distance $d_{m}$ given by the product of (2) and (7):

$$
d_{m}=\frac{1.5 \cdot \kappa \cdot \lambda^{2} \cdot \eta}{g \cdot \Delta \rho \cdot k}
$$

The depth, $d_{c}$, of the initial segregation from the top of the intrusion is the distance that the 'knee' of the error function temperature profile has travelled downward during $t_{p}$. Since the chill zone velocity, $V_{c}$, is proportional to $V_{s}$ (6) also implies that the average chill velocity, $\bar{V}_{c}$, is twice the instanta- 
TABLE 2. Representative Numerical Parameters

\begin{tabular}{clll}
\hline$T_{i}-T_{0},{ }^{\circ} \mathrm{C}$ & $f$ & $\lambda$ & $V_{c} / V_{s}$ \\
\hline 185 & 0.3 & 0.0835 & 5.90 \\
165 & 0.2 & 0.227 & 2.56 \\
145 & 0.1 & 0.481 & 1.59 \\
127 & 0.01 & 1.27 & 1.07 \\
125.4 & 0.002 & 1.71 & 1.05
\end{tabular}

$T_{i}$ is intrusion temperature. $T_{0}$ is country rock temperature. $\lambda$ and $V_{c} / V_{s}$ were calculated using the following parameters: $T_{s}-T_{o}=$ $125^{\circ} \mathrm{C}$, where $T_{s}$ is the solidus temperature; $C$ (heat capacity) $=0.3$ $\mathrm{cal} / \mathrm{g}{ }^{\circ} \mathrm{C} ; L$ (latent heat of fusion/melting interval of intrusion) $=0.5$ $\mathrm{cal} / \mathrm{g}{ }^{\circ} \mathrm{C}$.

neous chill velocity. It follows from the criterion for segregation, $V_{c}=V_{m}$, that $d_{c}$, given by the product of $t_{p}$ and $\nabla_{c}$, is twice $d_{m}$.

The total reservoir thickness, $l_{c}$, involved in producing an initial segregation is then the sum of $d_{m}$ and $d_{c}$ :

$$
l_{c}=d_{m}+d_{c}=d_{m}+2 d_{m}=\frac{4.5 \cdot \kappa \cdot \lambda^{2} \cdot \eta}{g \cdot \Delta \rho \cdot k}
$$

For a reservoir of this critical thickness, melt just begins to separate completely from matrix at a depth $d_{c}$ in the reservoir, the material above $d_{c}$ having cooled and partially solidified. Melt that has reached the pool at $d_{c}$ has travelled a distance $d_{m}$ from below. For reservoirs of greater thickness (i.e., $l>l_{c}$ ), segregation also occurs on the timescale given by (7). For reservoirs of less than the critical thickness $\left(l<l_{c}\right)$, the reservoir freezes before melt can segregate.

The trade off between freezing and percolation that controls the segregation process can be characterized succinctly by the dimensionless number $\xi$ found by dividing the time it would take to freeze the reservoir by the time it would take for melt to percolate across the reservoir [Walker, 1978]:

$$
\xi \equiv \frac{\Delta \rho \cdot g \cdot l \cdot k}{4 \cdot \kappa \cdot \lambda^{2} \cdot \eta}=\frac{l / \bar{V}_{s}}{l / V_{m}}
$$

For values of $\xi$ greater than a critical $\xi_{c}$ of order unity (1.1 for the parameters used above and in the remainder of this treatment), a partially molten reservoir is expected to develop a horizon of completely segregated liquid. For $\xi<\xi_{c}$ the reservoir is expected to be stable and not to develop a segregation of melt before freezing. Note that for $\xi=\xi_{c}, l_{c}$ is the solution to $(10)$.

It is clear from (10) that $\Delta \rho$ is not the only parameter that controls melt stability. If, for example, as a result of a very large $l, \xi$ exceeds the stability limit, $\xi_{c}$, by several orders of magnitude - as it does for many combinations of parameters plausible for the LVZ - then $\Delta \rho$ must be reduced several orders of magnitude to stabilize the LVZ. It may be unreasonable to expect $\Delta \rho$ to decrease by several orders of magnitude from values less than $1 \mathrm{~g} / \mathrm{cm}^{3}$ and to maintain these low values over the depth of the LVZ. Although decreasing $\Delta \rho$ by compression qualitatively leads to melt stabilization, it may not be quantitatively adequate for suppressing the potential instabilities in the LVZ. However, for small $l$, as in a rising diapir, melt compression may play a more important role.

As discussed above, the critical thickness, and the time scale required to begin a segregation depend on the parameters controlling the freezing and percolation rates. This may be seen by solving (10) for the density contrast required to make a reservoir unstable:

$$
\Delta \rho_{c}=\frac{\xi_{c} \cdot 4 \cdot \kappa \cdot \lambda^{2} \cdot \eta}{g \cdot l_{c} \cdot k}
$$

Substitution of (11) into (7) gives the time for forming an initial segregation when $l$ is the critical thickness:

$$
t_{0}=\frac{0.09 \cdot l_{c}^{2}}{\xi_{c}^{2} \cdot \kappa \cdot \lambda^{2}}=\frac{0.07 \cdot l_{c}^{2}}{\kappa \cdot \lambda^{2}}
$$

In this form, later used in calculating cooling times, $t_{0}$ does not depend explicitly on the parameters controlling melt velocity $(g, \Delta \rho, k$ or $\eta)$ but only on those parameters controlling cooling time.

We must now consider the trade off between melt motion and crystalline matrix accommodation. For melt to percolate upward within a bounded layer, melt channels must contract at the base and expand at the top of the layer by deformation of the crystalline matrix. Part of the stress resulting from the differential buoyancy of the melt drives the viscous melt through the matrix while part deforms the matrix itself. When deformation of the matrix is the limiting factor, the stress at the top of a fluid column of height $h$ is

$$
\sigma=\Delta \rho \cdot g \cdot \frac{h}{2}
$$

The factor of 2 is included to keep the stress distribution symmetrical about the midpoint of the column of fluid. The rate at which the deformation occurs depends upon this stress. The exact dependence of strain rate, $\dot{\gamma}$, on stress depends on such factors as temperature, confining pressure, crystalline material, and deformation mechanism but generally has the form [Ashby and Verrall, 1978]

$$
\dot{\gamma}=s_{0} \cdot\left(\Delta \rho \cdot g \cdot \frac{h}{2}\right)^{n}
$$

We shall assume that the crystalline material in mantle source regions is dominantly olivine at temperatures near the peridotite solidus for the purposes of this analysis. For many problems such as ours, Ashby and Verrall [1978] have predicted that strain rate will have contributions from both power law creep and diffusional flow. Consequently, we approximate (14) with a second power dependence of strain rate on stress $(n=2)$ and choose a representative value $\left(10^{-26} \mathrm{cgs}\right)$ for $s_{0}$, the preexponential constant in the strain rate equation (14). A more sophisticated analysis would include a more detailed characterization of $n$ and $s_{0}$ and their dependence on temperature, pressure and grain size. However, given the uncertainties in the deformation data and their extrapolations, we feel that our approximation is adequate for the purpose of assessing the relative importance of the various parameters controlling melt segregation.

To initiate a complete segregation at $d_{c}$, the melt fraction must increase to a critical value, $f_{d}$ at which point the grains forming the matrix disaggregate since they no longer touch. To accommodate this increase in $f$, the crystals must deform by an amount $\gamma_{d}$. If we assume that the horizontal distance between grain centers remains constant so that crystals deform by changing their vertical dimensions, $\gamma_{d}$ is given by $\varepsilon_{d}=\left(f_{d}-\right.$ $f) /\left(1-f_{d}\right)$. Taking $f_{d}$ as 0.5 gives $t_{d}$, the timescale on which deformation of the matrix occurs:

$$
t_{d}=\frac{4 \cdot(1-2 f)}{s_{0} \cdot(\Delta \rho \cdot g \cdot l)^{2}}
$$


Several approximations are associated with the formulation of the deformation time scale given in (15). The height of the fluid column that is responsible for the stress giving rise to the deformation is given in (15) as $l$, the reservoir or source region thickness. This is roughly appropriate when $l$ exceeds $l_{c}$ by more than a small amount, but if $l=l_{c}$, then the appropriate height is $d_{m}$, which according to (9) is on the order of $1 / 3$ of $l_{c}$. In this case, (15), as formulated, would represent a lower limit for $t_{\phi}$ with the actual time scale being a factor of 9 higher. We have taken $f_{d}$ to be 0.5 in (15); the true value is unknown, but is probably in the range $0.3-0.6$. Another assumption implicit in (15) is that the segregation of liquid from the disaggregated crystals at $f=f_{d}$ is very rapid. We have also assumed a given crystal deformation geometry to obtain $\gamma_{d}$, but others give comparable results. Given the uncertainties in parameters in (14) and their effects on $t_{d}$, these approximations are adequate for our purposes.

Another dimensionless quantity can be formulated by taking the ratio of the percolation and deformation time scales with the requirement that $l>l_{c}$ so that percolation can lead to melt segregation. Dividing (7) by (15),

$$
\Omega=\frac{t_{p}}{t_{d}}=\frac{0.37 \cdot \kappa \cdot s_{0}}{(1-2 f)} \cdot\left(\frac{l \cdot \lambda \cdot \eta}{k}\right)^{2}
$$

For $\Omega<1$ the segregation rate is controlled primarily by the deformation time scale while for $\Omega>1$ segregation is controlled primarily by the percolation rate.

Figure 4 shows the time to begin forming a melt segregation as a function of the initial melt concentration for two values of the density contrast for a $1 \mathrm{~km}$ thick layer. The other parameters are fixed. For the curve of $\Delta \rho=1 \mathrm{~g} / \mathrm{cm}^{3}$, two portions of the curve are seen. The steeply sloping curve of segregation time versus $f$ is controlled by percolation rate and is calculated from (7). The more melt initially present, the faster it collects. The nearly flat portion of the curve is controlled by the matrix deformation rate and is calculated from (15). The collection rate is relatively insensitive to the amount of melt present when matrix deformation is the limiting process. The intersection of the two curve segments is characterized by $\Omega=$ 1 from (16). Since (16) is independent of $\Delta \rho$, the intersections occur at the same value of $f$. The hatched curve marked cooling limit corresponds to the case where $l=l_{c}$ and is calculated from (12). It denotes the time scales on which melt can escape from a $\mathrm{km}$ thick reservoir before being trapped by freezing. The portion of the steep percolation-limited curve segment below this hatched boundary corresponds to solutions of (7) for which $l_{c}>l$ so that melt cannot escape.

Also shown in Figure 4 is a curve for $\Delta \rho=0.1 \mathrm{~g} / \mathrm{cm}^{3}$. In this case both segments of the curve fall below the cooling limit so that melt does not segregate. This provides an example of melt stabilization by reducing the density contrast driving percolation and deformation. We wish now to explore the range of conditions under which this stabilization may be encountered.

Figure 5 shows melt segregation times as a function of $\Delta \rho$ for various values of $f$. These contours of $f$ are again calculated from (7) which is independent of $l$. However, neither of the segregation limits imposed by reservoir cooling or matrix stiffness is independent of $l$. Therefore, these limits are calculated for $l=100 \mathrm{~km}$ appropriate to the $\mathrm{LVZ}$, for $l=10 \mathrm{~km}$, and for $l=1 \mathrm{~km}$ appropriate to a small partially molten diapir. Values of the other parameters are fixed $(R=1 \mathrm{~mm}, \eta=$

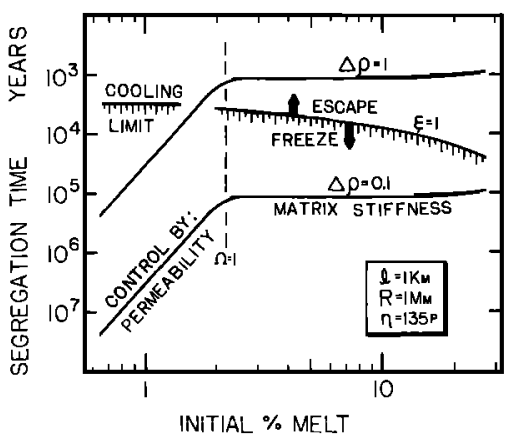

Fig. 4. Segregation time as a function of initial melt fraction for two values of $\Delta \rho$. Cooling limit curve calculated from (12). Above curve, melt can escape; below, it cannot. Entire curve for $\Delta \rho=0.1 \mathrm{~g}$ / $\mathrm{cm}^{3}$ is below cooling limit so that segregation does not, in fact, occur. Segment of curves primarily controlled by permeability $(\Omega>1)$ and matrix stiffness $(\Omega<1$ ) calculated from (7) and (15), respectively.

135 poise, etc.). The hatched cooling curve limits for the three values of $l$ are calculated from (12) as before. The ruled matrix stiffness limits are calculated in the following way. Solving (16) for $\Omega=1$ and substituting (3) we find that matrix stiffness becomes the limiting process for melt segregation when

$$
\frac{f^{4} \cdot(1-2 f)}{\lambda^{2}}=0.37 \cdot \kappa \cdot s_{0} \cdot\left(\frac{l \cdot \eta \cdot \chi}{R^{2}}\right)^{2}
$$

To place the stiffness limits on Figure 5 a solution of (17) for $f$ is found. For example, when $l=100 \mathrm{~km}, f \approx 17 \%$ satisfies (17) and so the contour of stiffness limit in a $100 \mathrm{~km}$ reservoir is placed accordingly. Reference to Figure 4 shows that for $f>$ $f_{\Omega=1}$ the segregation time varies little with $f$. Hence $f$ contours for $f \geqslant 17 \%$ are schematically bunched together along this boundary. Likewise for $l=1 \mathrm{~km}$ the contours for $f \geq 2.2 \%$ are bunched together along the stiffness boundary for $l=1 \mathrm{~km}$.

We have in Figure 5 a series of wedge-shaped areas for different values of $l$. The areas within the wedges correspond to situations where melt segregates. The areas above the wedges correspond to freezing preventing segregation. The areas to the lower right of the wedges correspond to the absence of $f$ contours since they are compressed on the lower edge of the wedge by matrix stiffness. The $\Delta \rho$ at the point of the wedge, $\Delta \rho_{\omega}$, is the lower limit compatible with melt segregation for each reservoir thickness for these choices of parameters. These $\Delta \rho$ limits on melt segregation are determined primarily by matrix stiffness. By equating (12) and (15) and setting $l=l_{c}$ and solving for $\Delta \rho_{w}$

$$
\Delta \rho_{\omega}=\frac{7.3 \cdot \lambda}{g \cdot l_{c}^{2}} \cdot\left[\frac{(1-2 f) \cdot \kappa}{s_{0}}\right]^{1 / 2}
$$

This approximation is valid for $f \leqslant 30 \%$ melt, i.e., for all $f$ of physical interest. Although it is not explicit in this relation, $\Delta \rho_{\omega}$ depends implicitly on parameters such as viscosity and permeability through (9).

\section{Discussion}

For any particular choice of parameters, the expected mode and time scale of melt segregation may be characterized as follows. First, (10) is used to calculate $\xi$. If $\xi>\xi_{c} \cong 1.1$ then melt should segregate unless matrix stiffness interferes. To check this possibility, (9) is used to calculate $l_{c}$ and (18) is used 


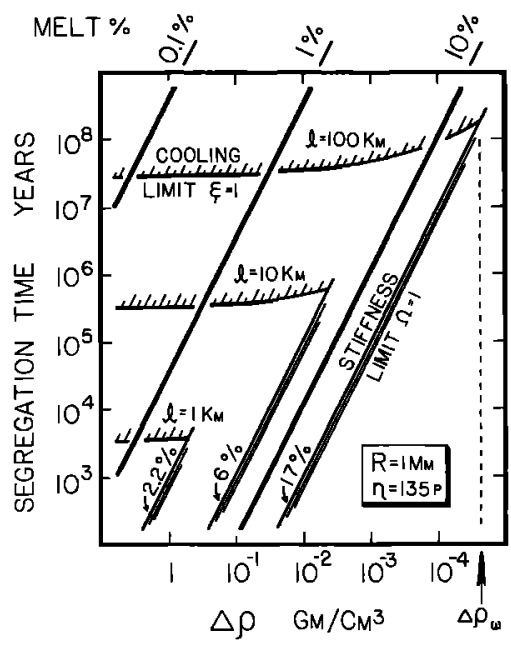

Fig. 5. Segregation time as a function of the density contrast driving segregation for different values of the initial melt fraction. Bounding wedges for three different thicknesses of plumbing systems are shown. Solutions within the wedges allow segregation. For each $l$ there is a $\Delta \rho_{\omega}$ below which melt cannot segregate because the solutions fall outside the wedge. The smaller the plumbing system, the larger $\Delta \rho$ must be to allow segregation, and the more important matrix stiffness becomes as the segregation-limiting process. Small plumbing systems are harder to flush than big ones.

to calculate $\Delta \rho_{\omega}$. If the $\Delta \rho$ tested is less than $\Delta \rho_{\omega}$ then melt escape is prevented by matrix stiffness. But if $\Delta \rho>\Delta \rho_{\omega}$ melt segregates. Using (16) one discovers whether $\Omega>1$ or $\Omega<1$. If $\Omega$ $>1$ then percolation controls the segregation rate and the time scale is given by (7). But if $\Omega<1$ then matrix stiffness controls the segregation rate and the time scale is given by (15). The various fields on Figure 5 give graphical solutions for these procedures.

As an example of the use of Figure 5 , take $\Delta \rho$ as $0.1 \mathrm{~g} / \mathrm{cm}^{3}$ and $f$ as $1 \%$. The time for melt segregation can be read as about $3 \times 10^{6}$ years. This time appears midway (logarithmically) between the cooling limits for $10 \mathrm{~km}$ and $100 \mathrm{~km}$ thick layers and to the left of the stiffness limit for all layers plotted. Thus matrix deformation is not a problem, but melt only segregates for layers thicker than about $30 \mathrm{~km}$. The melt segregation time will be $3 \times 10^{6}$ years for any layer thicker than this critical value, while thinner layers will freeze completely.

One important feature of Figure 5 is that the wedge tips limit the possible values of $\Delta \rho$ consistent with melt segregation. The existence of a limiting $\Delta \rho_{\omega}$ does not depend on the actual values assumed for the other parameters. However, the value of $\Delta \rho_{\omega}$ does depend on these values assumed. Figure 5 and (18) give the results for a particular set of parameters thought to be plausible for segregation of primitive melts from a source region in the earth's mantle. At $l=100 \mathrm{~km}$ (LVZ) we see that the limiting value of $\Delta \rho_{\omega}$ is $10^{-4}$ to $10^{-5} \mathrm{~g} / \mathrm{cm}^{3}$. Reference to Figure 2 shows that differential melt compression may bring $\Delta \rho$ to such small values but that they are not likely to be maintained over the depth interval of the LVZ. Melt compression may thus be able to stabilize part of the LVZ for all $f$ but probably not the whole layer.

In contrast to the situation for $l=100 \mathrm{~km}$, smaller source regions (e.g., $l=1 \mathrm{~km}$ ) may very well be stabilized by melt compression. For $l=1 \mathrm{~km}, \Delta \rho_{\omega}$ is $1-10^{-1} \mathrm{~g} / \mathrm{cm}^{3}$. That is to say that $\Delta \rho$ must be substantial is melt is to segregate. At smaller $l$, matrix stiffness becomes more important as the limiting proc- ess of melt segregation. At $l=100 \mathrm{~km}, f$ has to be $17 \%$ before matrix stiffness becomes a problem, however for $l=1 \mathrm{~km}, f$ need only be $2.2 \%$ for matrix stiffness to be the limiting process.

Waff [1980] has suggested a mechanism in which melt in the LVZ can be segmented into horizontal strata. For such a system of individual thin layers melt stability might be imposed then by the stiffness of the matrix that would need to be overcome by a larger $\Delta \rho$ than melt compression would allow. Clearly, if the permeability of the LVZ can be segmented into thin layers then melt can be stabilized there, and the fraction of melt present need not be small.

Our conclusions about melt stability in an $l=100 \mathrm{~km} \mathrm{LVZ}$ in the presence of a limiting $\Delta \rho_{\omega}$ and melt compression may be amended if we restrict ourselves to considering smaller $f$ than the one associated with $\Delta \rho_{\omega}$. For instance, Figure 5 shows that for $f=1 \%, \Delta \rho$ need only be $10^{-1}$ to $10^{-2} \mathrm{~g} / \mathrm{cm}^{3}$ to inhibit segregation. Melt compression may be capable of reducing $\Delta \rho$ to this sort of value over the depth range of the $L V Z$ and hence may contribute toward stabilizing melt in the LVZ if melt is present in small amounts.

To summarize, the dilemma of melt stability in the LVZ pointed out by Walker et al. [1978] remains for certain choices of parameters. However, melt fractions at the lower end $(f \sim$ $1 \%$ ) of the geophysically acceptable range could be stabilized by melt compression given the parameters used in Figure 5. However, larger $\boldsymbol{R}$ and smaller $\boldsymbol{\eta}$ are equally plausible for the LVZ, in which case it would be difficult to stabilize melt in the LVZ even if $\Delta \rho$ is very small. Alternately, reducing the size of the 'plumbing system' ( $l$ ), for instance by segmenting permeability [Waff, 1980], can easily stabilize substantial fractions of melt.

One or two implications of the control of $l$ on melt stability are worth emphasizing. Thin source regions are difficult to flush; they can trap substantial amounts of melt, principally through matrix stiffiness [Walker et al., 1979]. For instance consider a km-thick stack of permeable cumulates with $10 \%$ interstitial melt between mm-sized crystals. Although the potential percolation velocity is quite high $\left(V_{m} \cong 30 \mathrm{~cm} / \mathrm{yr}\right)$ for $\Delta \rho=0.1 \mathrm{~g} / \mathrm{cm}^{3}$, we find that crystal stiffness limits the segregation and that very little flow occurs. Likewise, the segregation process that occurs in ascending diapirs is sensitive to the thickness of the partially molten zone within the diapir. For 'small' diapirs with limited partially molten zones, segregation is inhibited by the crystalline body of the diapir. This is especially true if the diapir is at a depth where compression significantly reduces $\Delta \rho$. Consequently small, deep-starting diapirs could build up substantial fractions $(f \geq 30 \%$ ) of melt within themselves without segregating - until such time as ascent decompresses the diapir and $\Delta \rho$ exceeds $\Delta \rho_{\omega}$ of $f$ becomes so large that the crystalline network is destroyed. At this point melt may segregate quite rapidly. By contrast, 'large' diapirs would tend to leak during their ascent because the thicker partially molten zone reduces $\Delta \rho_{\omega}$, diminishing the importance of matrix stiffness as a limiting process. They would not build up large fractions of melt without segregating. This suggests a possible mechanism for producing the large fractions of melting suspected to be involved in the genesis of komatiite [Walker et al., 1980]: If the instability leading to diapir ascent occurs at abnormally great depths, at high temperature, and reduced mantle viscosity - conditions possibly relevant to the Archean-the size required to initiate a diapir rise may be relatively small. At great depth and compression, these small 
blobs could then be suited to storing large fractions of melt before they decompress and segregate.

The diminishing density contrast between basic liquids and mantle minerals with increasing pressure (Figures 2 and 3) and the analysis of melt segregation summarized in Figure 5 lead to additional generalizations applicable to petrogenetic problems.

The greater the depth of a partially molten source region, the smaller the density contrast between melt and residual crystals. The time scale for melt segregation increases as the reciprocal of $\Delta \rho^{2}$ (7). As $\Delta \rho \rightarrow 0$, melts will be less likely to segregate from residual crystals over the relevant geologic time, leading to the prediction that there could be a rough, natural limit to the depth from which dry, basic melts can be derived. Reference to Figure 2 suggests that this critical depth might be between 100 and $200 \mathrm{~km}$ (30-70 kbar) since this is the region in which $\Delta \rho \rightarrow 0$. Melts produced at greater depths, unless representing very large degrees of partial melting, could remain in their source regions, unsegregated from the residual crystals for geologically long times. Suppose the source region were part of a rising diapir: the melt would remain in the source region, continuously re-equilibrating with the residual phases, until the diapir has risen far enough for $\Delta \rho$ to become large enough for the source region to unload the partial melt or until the degree of partial melting becomes large enough for the framework of residual crystals to disintegrate. At this point melt segregation would occur relatively rapidly even if $\Delta \rho \rightarrow 0$. Figure 5 suggests that these effects will be more important the smaller the size of the source region; it will be of minimal significance in melt zones hundreds of kilometers thick, but it will be applicable to diapirlike bodies a few to tens of kilometers thick. (We emphasize that the problem that we consider is the segregation of melt within a partially molten diapir, not the problem of how to initiate and propagate diapir migration itself [e.g., Marsh, 1978].)

There may indeed be an upper limit to the depths from which dry basic melts are derived. Based on geobarometry of xenoliths in continental and oceanic basalts, most of which are spinel- rather than garnet-bearing, most nodules are actually derived from $\mathbf{3 0}$ kbar or less; in fact, there may be a sharp cutoff in nodule abundance at this pressure (see Figure 10 of Mercier and Carter [1975]). Although other explanations of this observation can be readily envisioned, our analysis suggests that the rarity of nodules and basaltic magmas derived from pressures greater than $30 \mathrm{kbar}$ could be related to the difficulty of segregating magmas from source regions at higher pressures (note that geobarometry of nodules only supplies a lower limit to the depth of generation of the melt that contains it). The only magmas clearly derived from depths greater than $100 \mathrm{~km}$ are volatile-rich magmas such as kimberlites, and these are rare relative to typical basalts presumably derived from shallower depths. These volatile-rich magmas may be more easily separable from their source regions at great depths because (1) they are probably intrinsically less dense and perhaps less viscous than typical basalts due to their enrichment in volatiles (but they are also probably more compressible for the same reason) and (2) magma segregation may be facilitated by the evolution of a free $\mathrm{H}_{2} \mathrm{O}-\mathrm{CO}_{2}$-rich fluid phase in the source regions. If our analysis is valid, it would suggest that even if basic melts are produced at depths greater than $100 \mathrm{~km}$, they might not escape upwards and erupt unless the degree of partial melting is very high. Only unusual melts, rich in volatiles or low in density for another compositional reason, or produced by very high degrees of partial melting are to be expected from depths greater than $100-200 \mathrm{~km}$.

If the concept of an upper limit to the depth of magma segregation controlled by the $l / \Delta \rho^{2}$ dependence of the time scale for melt segregation is valid, it should be applicable to other planets as well as the earth [Walker et al., 1979]. We would expect the maximum depth of dry magma segregation to differ from planet to planet, but the pressures corresponding to these depths should not vary. The petrogenesis of lunar ultramafic glasses is controversial, but Delano [1980] suggests that the Apollo 15 red glass segregated from a peridotite source region at a pressure of $25 \mathrm{kbar}$ corresponding to a depth of about 500 $\mathrm{km}$ within the moon; this is the greatest depth proposed for lunar basalt petrogenesis. McGetchin and Smyth [1978] summarized the line of reasoning, based principally on an analysis of volcano heights, that suggests a depth of Martian magma segregation of $150-250 \mathrm{~km}$, corresponding to a pressure of 20-32 kbar.

The deepest dry basaltic magmas on earth and from the moon, and the inferred maximum depth of Martian magma segregation, thus all appear to come from a similar pressure range, 25-35 kbar. This similarity on all three planets, if borne out, would be consistent with the hypothesis that the diminished density contrast between melt and peridotite reaches a critical value at near $30 \mathrm{kbar}$, such that melt segregation at greater pressures is rarely achieved. To be sure, there are alternative explanations of this observation; for example, this may represent a thermal effect, such that the solidus of dry peridotite is rarely achieved at pressures greater than 25-35 kbar. Although there may be other factors involved, one predicted consequence of a diminishing $\Delta \rho$ with increasing pressure is indeed observed.

We have predicted that melts produced at depths shallower than $100-200 \mathrm{~km}$ are more likely to segregate from residual crystals, escape upwards, and erupt than are melts at deeper levels. This suggests that the region above and including the upper parts of the LVZ could represent a drainage zone, while the lower parts of the LVZ represent a trap from which melts rarely escape, unless other factors, such as large degrees of melting or unusual (e.g., volatile-rich) melt compositions, aid melt segregation. This might explain, in part, why depleted, granular lherzolites are derived from shallower levels than less depleted, sheared lherzolites under South Africa [Boyd and Nixon, 1975]. The granular lherzolites come from shallower regions where melt drainage was more efficient due to a large $\Delta \rho$, while melt segregation from the deeper levels of the sheared lherzolites was inhibited as $\Delta \rho \rightarrow 0$. The boundary between granular and sheared lherzolites, at about $150 \mathrm{~km}$ (50 kbar), is consistent with Figure 2. The full explanation of the relationship between sheared and granular lherzolites must be more complex than this based on their trace element distributions [Shimizu, 1975] but these may largely reflect the effects of mantle metasomatism [e.g., Mysen, 1978]. The decrease in density contrast with increasing pressure may also contribute to an explanation of how regions of the mantle could remain 'undepleted' throughout geological time [Wasserburg and DePaolo, 1979]. Mantle below the critical depth would not release magmas even if partially molten, due to the small $\Delta \rho$. Thus, independent of melting events and thermal structure, mantle peridotite below this critical depth could remain undepleted. Only when undepleted material rises above 
the critical depth, either in diapirs or as part of a local or global convection pattern, will melt from 'undepleted' peridotite segregate and be available for eruption [ $O$ 'Connell and Hager, 1980]. 'Depleted' peridotite source regions can only form above the critical depth.

High pressure fractionation of melts might also be expected to be less efficient than low pressure fractionation if gravitational segregation is the major process in the fractionation of magmas en route to the surface since $\Delta \rho$ decreases with increasing pressure, although decreases in viscosity [Kushiro et al., 1976] would counteract this to some extent. However, this would not necessarily apply if nucleation and growth of crystals on conduit walls is an important process [e.g. Irving, 1980].

Some of the extrapolations of melt density to higher pressures shown in Figure 2 imply that dry basic melts may in fact become denser than residual peridotite at some pressure. Though this may be intuitively displeasing, it has previously been suggested by Anderson and Jordan [1970], and there is no theoretical reason why it could not be so. It is therefore worthwhile to consider briefly some of its possible implications. One is that there would be an absolute upper limit to the depth from which basaltic magmas could be derived, and not simply a limit such as that discussed above related to the time scale on which melt would segregate based on its density contrast. Melts, if generated in the region of the density cross-over would simply remain there indefinitely. Below the depth of the density cross-over, melts might actually segregate downwards. This could have important implications, especially during the early history of the earth and other planets when large portions of their mantles might have been molten, since it could imply that incompatible elements, including heat producing elements such as $K$ and $U$, might concentrate downwards rather than upwards into the crust and it could also result in an iron enrichment downward in the mantle. If basic melt drained downwards, it would crystallize and ultimately intersect its solidus. This could lead to the concentration of eclogite and perhaps the development of an eclogitic layer at some depth in the mantle at depths greater than $100-200 \mathrm{~km}$.

\section{CONCLUSIONS}

At low pressures, basaltic liquids are more compressible than the minerals in peridotites. Thus, the density contrast between them-the basic liquid being less dense than the peridotite-which plays a crucial role in many aspects of petrogenesis, diminishes with increasing pressure. This suggests that the greater the depth of a partially molten source region, the longer the time scale and the greater the difficulty in segregating the liquid from the residual crystals in these source regions. This leads to the prediction that there could be an upper limit to the depth from which basaltic magmas could be derived; liquids generated by melting in deeper source regions would segregate from their source regions with greater difficulty than those at shallow levels. There does indeed seem to be a rough upper limit to the depth from which basaltic magmas are derived on earth, at about 30-40 kbar. Similar upper limits may exist on the moon and on Mars, corresponding to different absolute depths but similar pressures, 25-35 kbar. Consideration of the factors involved in melt segregation suggests that small values of $\Delta \rho$ will be more effective in inhibiting melt segregation in small source regions than in large source regions. The difficulty of segregating melts from deep source regions may also explain, in part, why depleted lherzolites overlie undepleted lherzolites in South Africa; depleted mantle source regions can only form above a critical depth, because below this depth, melt will not segregate from the residue.

Other petrogenetic effects of the diminishing density contrast between melt and residual minerals with depth include the possibility of generating large degrees of partial melting in deep source regions; in a rising diapir, these large percentages of melt will unload when the density contrast increases suffciently to allow melt segregation. This effect will be enhanced in smaller diapirs and may be relevant to komatiite genesis. Also, if the degree of partial melting becomes large enough, the crystalline framework of the residue will be destroyed, and melt segregation will occur rapidly, even at small values of $\Delta \rho$.

If gravitational settling of crystals is an important fractionation process during the rise of magma towards the surface in conduits, the lower values of $\Delta \rho$ at depth might result in low pressure fractionation being dominant over high pressure fractionation in the evolution of the compositions of magmas erupted at the surface. If the density of basic melt ever actually exceeds that of the residual crystals in the source region, this could lead to an absolute upper limit on the depth from which magmas can be derived and the segregation of liquid and incompatible elements downwards, perhaps to form an olivine eclogite layer at some depth below $100-200 \mathrm{~km}$.

Acknowledgments. We wish to thank T. J. Ahrens, C. Herzberg, B. Kamb and D. Stevenson for helpful comments on preliminary versions of the manuscript. This work was supported by NSF grants OCE 79-09699, EAR 79-06321, EAR 79-23977, EAR 80-25643, and EAR 80-18819; NASA grant NGL 22-007-247; and the Committee on Experimental Geology and Geophysics of Harvard University. Contribution 3454, Division of Geological and Planetary Sciences, California Institute of Technology, Pasadena, California.

\section{REFERENCES}

Ahrens, T. J., Petrologic properties of the upper $670 \mathrm{~km}$ of the earth's mantle; geophysical implications, Phys. Earth Planet. Interiors, 7, 167-186, 1973.

Anderson, D. L., and T. Jordan, The composition of the lower mantle, Phys. Earth Planet. Interiors, 3, 23-35, 1970.

Anderson, O. L., A scaling law for $K_{0}{ }^{\prime}$ for silicates with constant mean atomic mass, Earth Planet. Sci. Lett., 20, 73-76, 1973.

Anderson, $\mathrm{O}$. L., and J. E. Nafe, The bulk modulus-volume relationship for oxide compounds and related geophysical problems, $J$. Geophys. Res., 70, 3951-3963, 1965.

Anderson, O. L., E. Schreiber, R. C. Liebermann, and N. Soga, Some elastic constant data on minerals relevant to geophysics, Rev. Geophys. Space Phys., 6, 491-524, 1968.

Ashby, M. F., and R. A. Verrall, Micromechanisms of flow and fracture, and their relevance to the rheology of the upper mantle, Phil. Trans. R. Soc. London, Ser. A, 288, 59-95, 1978.

Baidov, V. V., and L. L. Kunin, Speed of ultrasound and compressibility of molten silica, Sov. Phys. Dokl. Engl. Transl., 13, 64-65, 1968.

Bender, J. F., F. N. Hodges, and A. E. Bence, Petrogenesis of basalts from the Project FAMOUS area: Experimental study from 0 to 15 kbars, Earth Planet. Sci. Lett., 41, 277-302, 1978.

Bickle, M. J., C. E. Ford, and E. G. Nisbet, The petrogenesis of peridotitic komatiites: Evidence from high-pressure melting experiments, Earth Planet. Sci. Lett., 37, 97-106, 1977.

Birch, F., Elasticity and constitution of the earth's interior, $J$. Geophys. Res., 57, 227-286, 1952.

Bloom, H., and J. O. Bockris, The compressibilities of the silicates: $\mathrm{The}_{\mathrm{Li}} \mathrm{O}-\mathrm{SiO}_{2}$ system, J. Phys. Chem., 61, 515-518, 1957.

Bockris, J. O., and E. Kojonen, The compressibilities of certain molten alkali silicates and borates, J. Am. Chem. Soc., 82, 4493-4497, 1960.

Bottinga, Y., and D. F. Weill, Densities of liquid silicate systems calculated from partial molar volumes of oxide components, Am. J. Sci., 269, 169-182, 1970.

Boyd, F. R., and R. H. McCallister, Densities of fertile and sterile gar- 
net peridotites, Geophys. Res. Lett., 3, 509-512, 1976.

Boyd, F. R., and P. H. Nixon, Origins of the ultramafic nodules from some kimberlites of Northern Lesotho and the Monastery Mine, South Africa, Phys. Chem. Earth, 9, 431-454, 1975.

Bridgman, P. W., Thermodynamic properties of twelve liquids between $20^{\circ}$ and $80^{\circ}$ and up to $12,000 \mathrm{kgm}$. per sq. cm, Proc. Am. Acad. Arts Sci., 49, 49, 3-114, 1913.

Cameron, M. E., S. Sueno, C. T. Prewitt, and J. J. Papike, High-temperature crystal chemistry of acmite, diopside, hedenbergite, jadeite, spodumene, and ureyite, Am. Mineral., 58, 594-618, 1973.

Chung, D. H., On the equations of state of high-pressure solid phases, Earth Planet. Sci. Lett., 18, 125-132, 1973.

Clark, S. P., Jr., and A. E. Ringwood, Density distribution and constitution of the mantle, Rev. Geophys. Space Phys., 2, 35-88, 1964.

Delano, J. W., Apollo 15 red glass: Chemistry and liquidus phase relations, Lunar Planet. Sci, XI, 210-212, 1980.

Dorman, J., Seismic surface-wave data on the upper mantle, in The Earth's Crust and Upper Mantle, Geophys. Monogr. Ser., vol. 13, edited by P. J. Hart, AGU, Washington, D. C., 1969.

Dziewonski, A. M., A. L. Hales, and E. R. Lapwood, Parametrically simple earth models consistent with geophysical data, Phys. Earth Planet. Interiors, 10, 12-48, 1975.

Fujii, T., and I. Kushiro, Density, viscosity, and compressibility of basaltic liquid at high pressures, Year Book Carnegie Inst. Washington, 76, 419-424, 1977a.

Fujii, T., and I. Kushiro, Melting relations and viscosity of an abyssal tholeiite, Year Book Carnegie Inst. Washington, 76, 461-465, $1977 b$.

Graham, E. K., Jr., and G. R. Barsch, Elastic constants of single crystal forsterite as a function of temperature and pressure, $J$. Geophys. Res., 74, 5949-5960, 1969.

Green, D. H., W. O. Hibberson, and A. L. Jaques, Petrogenesis of mid-ocean ridge basalts, in The Earth: Its Origin, Structure and Evolution, edited by M. W. McElhinny, Academic, New York, 1979.

Hazen, R. M., Effects of temperature and pressure on the crystal structure of ferromagnesian olivine, Am. Mineral., 62, 286-295, 1977.

Howells, S., C. Begg, and M. J. O'Hara, Crystallization of some natural eclogites and garnetiferous ultrabasic rocks at high pressure and temperature, Phys. Chem. Earth, 9, 895-902, 1975.

Irvine, T. N., Definition of primitive liquid compositions for basic magmas, Year Book Carnegie Inst. Washington, 76, 454-461, 1977.

Irving, A. J., Petrology and geochemistry of composite ultramafic xenoliths in alkalic basalts and implications for magmatic processes within the mantle, $A m$. J. Sct., 280-A, 389-426, 1980.

Jaeger, J. C., The temperature in the neighborhood of a cooling intrusive sheet, $A m$. J. Sci., 255, 306-318, 1957.

Kumazawa, M., H. Furuhashi, and K. Iida, Seismic wave velocity in molten silicate at high temperature, Bull. Volcanol. Soc. Jpn., 9, 17 24, 1964.

Kushiro, I., H. S. Yoder, Jr., and B. O. Mysen, Viscosities of basalt and andesite melts at high pressures, $J$. Geophys. Res., 81, 63516356, 1976.

Laberge, N. L., V. V. Vasilescu, C. J. Montrose, and P. B. Macedo, Equilibrium compressibilities and density fluctuations in $\mathrm{K}_{2} \mathrm{O}-\mathrm{SiO}_{2}$ glasses, J. Am. Ceram. Soc., 56, 506-509, 1973.

Levien, L., C. T. Prewitt, and D. J. Weidner, Compression of pyrope, Am. Mineral., 64, 805-808, 1979.

Liebermann, R. C., and D. J. Mayson, Elastic properties of polycrystalline diopside $\left(\mathrm{CaMgSi}_{2} \mathrm{O}_{6}\right)$, Phys. Earth Planet. Interiors, 11 , P1-P4, 1976.

Manghnani, M. H., C. S. Rai, K. W. Katahara, and G. R. Olhoeft, Ultrasonic velocity and attenuation in basalt melt, in Anelasticity of the Mantle, International Union of Geodesy and Geophysics, Paris, in press, 1981.

Marsh, B. D., On the cooling of ascending andesitic magma, Phil. Trans. R. Soc. London, Ser. A, 288, 611-625, 1978.

McGetchin, T., and J. R. Smyth, The mantle of Mars: Some possible geological implications of its high density, Icarus, 34, 512-536, 1978.

Mercier, J. C., and N. L. Carter, Pyroxene geotherms, J. Geophys. Res., 80, 3349-3362, 1975.

Murase, T., and A. R. McBirney, Properties of some common igneous rocks and their melts at high temperatures, Geol. Soc. Am. Bull., 84, 3563-3592, 1973.

Murase, T., and T. Suzuki, Ultrasonic velocity of longitudinal waves in molten rocks, Hokkaido Univ. Fac. Sci. J., Ser. 7, 2, 273-285, 1966.
Murase, T., I. Kushiro, and T. Fujii, Compressional wave velocity in partially molten peridotite, Year Book Carnegie Inst. Washington, 76, 414-416, 1977.

Mysen, B. O., Experimental determination of crystal-vapor partition coefficients for rare earth elements to $\mathbf{3 0} \mathrm{kbar}$ pressure, Year Book Carnegie Inst. Washington, 79, 689-695, 1978.

Mysen, B. O., D. Virgo, and C. M. Scarfe, Relations between the anionic structure and viscosity of silicate melts-A Raman spectroscopic study, Am. Mineral., 65, 690-710, 1980.

Nelson, S. A., and I. S. E. Carmichael, Partial molar volumes of oxide components in silicate liquids, Contrib. Mineral. Petrol, 71,117 $124,1979$.

O'Connell, R. J., and B. H. Hager, Ridge migration and mantle differentiation (abstract), Eos Trans. AGU, 61, 373, 1980.

O'Hara, M. J., Are any ocean floor basalts primary magma?, Nature, $220,683-686,1968 a$.

O'Hara, M. J., The bearing of phase equilibria studies in synthetic and natural systems on the origin and evolution of basic and ultrabasic rocks, Earth Sci. Rev., 4, 69-133, 1968 b.

Olinger, B., Compression studies of forsterite $\left(\mathrm{Mg}_{2} \mathrm{SiO}_{4}\right)$ and enstatite $\left(\mathrm{MgSiO}_{3}\right)$, in High-Pressure Research, edited by $\mathrm{M}$. H. Manghnani and S.-I. Akimoto, pp. 325-334, Academic, New York, 1977

Peselnick, L., R. Meister, and W. H. Wilson, Pressure derivatives of elastic moduli of fused quartz to $10 \mathrm{~kb}$. J. Phys. Chem. Solids, 28 635-639, 1967.

Presnall, D. C., J. R. Dixon, T. H. O'Donnell, and S. A. Dixon, Generation of mid-ocean ridge tholeites, J. Petrol, 20, 3-35, 1979.

Scarfe, C. M., B. O. Mysen, and D. Virgo, Changes in viscosity and density of melts of sodium disilicate, sodium metasilicate, and diopside composition with pressure, Year Book Carnegie Inst. Washington, 78, 547-551, 1979.

Sharma, S. V., D. Virgo, and B. O. Mysen, Raman study of the coordination of aluminum in jadeite melts as a function of pressure, Am. Mineral., 64, 779-787, 1979.

Shimizu, N., Rare earth elements in garnets and clinopyroxene from garnet 1 herzolite nodules in kimberlites, Earth Planet. Sci. Lett., 25, 26-32, 1975 .

Skelton, E. F., High Pressure Science and Technology in Japan, Tokyo Sci. Monogr. Ser., Monogr. I, 109 pp., Office of Naval Research, Tokyo, 1978.

Skinner, B. J., Thermal expansion, Geol. Soc. Am. Mem., 97, 75-96, 1966.

Soga, N., Elastic constants of garnet under pressure and temperature, J. Geophys. Res., 72, 4227-4234, 1967.

Spetzler, H. A., M. D. Meyer, and T. Chan, Sound velocity and equation of state of liquid mercury and bismuth at simultaneous high pressure and temperature, High Temp. High Pressures, 7, 481-496, 1975.

Stolper, E., A phase diagram for mid-ocean ridge basalts: Preliminary results and implications for petrogenesis, Contrib. Mineral. Petrol. 74, 13-27, 1980.

Stolper, E., and D. Walker, Melt density and the average composition of basalt, Contrib. Mineral. Petrol., 74, 7-12, 1980.

Waff, H. S., Pressure-induced changes in magmatic liquids, Geophys. Res. Lett., 2, 193-196, 1975.

Waff, H. S., Vertical stratification of permeability in partial melts within the mantle, J. Geophys. Res., 85, 1815-1825, 1980.

Waff, H. S., and J. R. Bulau, Equilibrium fluid distribution in an ultramafic partial melt under hydrostatic stress conditions, $J$ Geophys. Res., 84, 6109-6114, 1979.

Walker, D., Stability of melt in permeable bodies (abstract), Eos Trans. $A G U, 59,1124,1978$.

Walker, D., E. M. Stolper, and J. F. Hays, A numerical treatment of melt/solid segregation: Size of the eucrite parent body and stability of the terrestrial low-velocity zone, J. Geophys. Res., 83, 6005-6013, 1978.

Walker, D., E. M. Stolper, and J. F. Hays, Limits on buoyancy-driven melt segregation, Abstr. Programs, 11, 533, 1979.

Walker, D., E. M. Stolper, and J. F. Hays, Komatiite petrogenesis and melt segregation (abstract), Eos Trans. AGU, 61, 385, 1980.

Wasserburg, G. J., and D. J. DePaolo, Models of earth structure inferred from neodymium and strontium isotopic abundances, Proc Natl. Acad Sci. USA, 76, 3594-3598, 1979.

(Received June 6, 1980; accepted September 18, 1980.) 